\title{
1 Abundant cold anticyclonic eddies and warm cyclonic eddies \\ in the global ocean
}

3

a State Key Laboratory of Satellite Ocean Environment Dynamics, Second Institute of Oceanography, Ministry of Natural Resources, Hangzhou, China

${ }^{b}$ Centre for Ocean and Atmospheric Sciences, School of Environmental Sciences, University of East Anglia, Norwich, United Kingdom ${ }^{c}$ Shanghai Marine Monitoring and Forecasting Center, Shanghai, China

${ }^{d}$ Southern Marine Science and Engineering Guangdong Laboratory, Zhuhai, China 
Mesoscale eddies are ubiquitous features of the global ocean circulation and play a key role in transporting ocean properties and modulating air-sea exchanges. Anticyclonic and cyclonic eddies are traditionally thought to be associated with anomalous warm and cold surface waters, respectively. Using satellite altimeter and microwave data, here we show that surface cold-core anticyclonic eddies (CAEs) and warm-core cyclonic eddies (WCEs) are surprisingly abundant in the global ocean about $20 \%$ of the eddies inferred from altimeter data are CAEs and WCEs. Composite analysis using Argo float profiles reveals that the cold cores of CAEs and warm cores of WCEs are generally confined in the upper 50 meters. Interestingly, CAEs and WCEs alter air-sea momentum and heat fluxes and modulate mixed layer depth and surface chlorophyll concentration in a way markedly different from the traditional warm-core anticyclonic and cold-core cyclonic eddies. Given their abundance, CAEs and WCEs need to be properly accounted for when assessing and parametrizing the role of ocean eddies in the Earth's climate system. 


\section{Introduction}

Satellite altimeter observations have revealed that the global ocean is full of energetic mesoscale features with spatial scales of tens to hundreds of kilometers, which were initially thought to be linear Rossby waves but later turned out to be nonlinear eddies (Chelton et al. 1996; Stammer 1997; Chelton et al. 2011a). These eddies play a crucial role in the Earth's climate system by shaping the large-scale ocean circulation, modulating air-sea fluxes, and transporting and redistributing biogeochemical tracers such as carbon and nutrients throughout the ocean (Klein and Lapeyre 2009; Greatbatch et al. 2010; Frenger et al. 2013). Over the past few decades, there have been a number of studies investigating the statistics, dynamics and energetics of mesoscale eddies (e.g., Zhai et al. 2010; Chelton et al. 2011a; Chaigneau et al. 2011; Ni et al. 2020a).

The traditional wisdom is that mesoscale anticyclonic eddies (AEs) and cyclonic eddies (CEs) are associated with, respectively, anomalous warm and cold surface and subsurface cores, with both characterized by surface-intensified potential vorticity (Hausmann and Czaja 2012; Frenger et al. 2013; Gaube et al. 2015). In this study we focus on a subset of AEs and CEs that are characterized by subsurface-intensified potential vorticity and sea surface temperature (SST) anomalies of opposite sign to the conventional eddies (Bashmachnikov et al. 2013; Assassi et al. 2016; Dilmahamod et al. 2018), i.e., AEs with SST colder (CAEs), and CEs with SST warmer (WCEs), than the surrounding water outside the eddies. Although CAEs and WCEs have been reported a few times in satellite observations in some boundary currents and marginal 
sea regions (e.g., Everett et al. 2012; Leyba et al. 2017; Sun et al. 2019; Liu et al. 2020), it is not clear how abundant these unconventional eddies are on the global scale. Furthermore, studies relying on satellite data alone provide no information of the subsurface structures of CAEs and WCEs. For instance, it is not clear whether the cold cores of CAEs and warm cores of WCEs found in satellite observations are confined very close to the sea surface or extend tens of, or even over a hundred, meters into the ocean interior.

Knowledge of the distribution and upper ocean structure of CAEs and WCEs in the global ocean may prove to be particularly important for understanding air-sea exchanges. The air-sea boundary layer is the channel by which the atmosphere and ocean interior are coupled and interact with each other. It is well known that mesoscale eddies can significantly modulate fluxes at the air-sea interface (Frenger et al. 2013; Gaube et al. 2015; Villas Bôas et al. 2015). For example, warm (cold) surface water usually associated with AEs (CEs) induces anomalous upward (downward) air-sea heat fluxes, which then strengthen (weaken) surface wind stress by increasing (decreasing) vertical turbulent mixing and downward momentum transport in the atmosphere boundary layer (Chelton and Xie 2010; Frenger et al. 2013; Ni et al. 2020b). Moreover, AEs and CEs have been reported to deepen and shoal the surface mixed layer, respectively (Dufois et al. 2016; Hausmann et al. 2017; Gaube et al. 2018), as a result of ocean convective mixing triggered by anomalous air-sea heat fluxes associated with eddy-induced SST anomalies (Williams 1988). Mesoscale eddies are also found to induce distinct upper ocean biological responses owing to different mechanisms in 
different regions (McGillicuddy et al. 2007; Klein and Lapeyre 2009; Gaube et al. 2013). For instance, isopycnal displacement associated with mesoscale eddies can result in positive (negative) chlorophyll anomalies within CEs (AEs) (Klein and Lapeyre 2009), while eddy-wind interaction and eddy SST-induced convective mixing can lead to opposite chlorophyll response inside the eddies (Gaube et al. 2015; Dufois et al. 2016). However, the global impacts of CAEs and WCEs on air-sea fluxes, mixed layer depth (MLD) and surface chlorophyll concentration are yet open questions.

The present paper is organized as follows. Data used in this study and how they are processed before the analysis are described in section 2 , mesoscale eddies detected and classified from satellite-derived sea level anomaly (SLA) and SST data are analyzed in section 3, and three-dimensional eddy structures composited from satellite observations and Argo measurements are shown in section 4. In section 5 we compare impacts of CAEs and WCEs and conventional AEs and CEs on air-sea fluxes and in section 6 we investigate the mixed layer and biological responses induced by different types of eddies. Finally, conclusions are provided in section 7.

\section{Data processing}

The daily SLA data provided by Copernicus Marine Environment Monitoring Service (http://marine.copernicus.eu/) on a global $1 / 4^{\circ} \times 1 / 4^{\circ}$ grid are used in this study for a 20-year period from January 1998 to December 2017. Each SLA map is highpass-filtered using a Gaussian filter function with a half-power cutoff wavelength of $10^{\circ}$ to remove large-scale signals associated with heating/cooling and wind forcing before 
we apply the procedure of eddy identification (Chelton et al. 2011a; Xu et al. 2016; Ni et al. 2020a).

The global microwave SST data for the same 20-year period are obtained from the Remote Sensing Systems (http://www.remss.com/), and near-surface turbulent heat flux and QuikSCAT scatterometer wind stress data are obtained from the French Research Institute for Exploitation of the Sea (http://cersat.ifremer.fr/) for the period of 2000-2009. Both datasets are provided with a spatial resolution of $0.25^{\circ}$ and a temporal resolution of one day. Note that these latent heat fluxes (LHF) and sensible heat fluxes (SHF), two primary processes by which the ocean releases heat to the atmosphere, are derived from the bulk formulae mainly using satellite observations (Bentamy et al. 2013; Villas Bôas et al. 2015). To isolate mesoscale air-sea signals, the SST, turbulent heat flux and wind stress data are spatially high-pass-filtered with a half-power cutoff wavelength of $6^{\circ}$ (Chelton et al. 2011b; Gaube et al. 2013; 2015).

The Argo float data are obtained from the Argo Real-time Data Center (http://www.argo.org.cn/) for the same 20-year period. A total of about 1.1 million quality-controlled Argo float profiles with records at depths shallower than $10 \mathrm{~m}$ and deeper than $1000 \mathrm{~m}$ are selected. For each Argo profile, potential density is calculated from temperature and salinity and the potential density anomaly is obtained by subtracting from each Argo profile a local climatological profile interpolated from the $1 / 2^{\circ} \times 1 / 2^{\circ}$ CARS2009 dataset (http://www.marine.csiro.au/ dunn/cars2009/; Chaigneau et al. 2011). The MLD of each Argo profile is defined as the depth where 
114 the temperature differs by $0.2^{\circ} \mathrm{C}$ from the temperature at $10-\mathrm{m}$ depth (de Boyer 115 Montégut et al. 2004; Dufois et al. 2016; Hausmann et al. 2017). To obtain the MLD 116 anomaly, a monthly climatological mean is removed from the original MLD of each 117 Argo profile (Gaube et al. 2018). This climatological mean is computed by averaging 118 all the Argo profiles' MLD during the same month within a $6^{\circ} \times 6^{\circ}$ bin centered at the 119 profile under consideration. Project (http://hermes.acri.fr/index.php?class=archive) on a $0.25^{\circ} \times 0.25^{\circ}$ grid for the same 20-year period. Following Chelton et al. (2011b), the original chlorophyll data are first $\log _{10}$ transformed because of the skewed distribution of chlorophyll and the multi-year mean is then removed. After that, the $\log _{10}$-transformed chlorophyll fields are spatially high-pass-filtered with a half-power cutoff wavelength of $6^{\circ}$ to extract

\section{Global distribution}

This work starts by identifying mesoscale eddies from the daily SLA maps using an eddy detection method that is based on the SLA geometry (Chelton et al. 2011a; Chaigneau et al. 2011; Ni et al. 2020a). Contours are extracted from the high-passfiltered SLA maps at an interval of $1 \mathrm{~cm}$ (Chelton et al. 2011a). The center of an eddy is defined as the average position of the innermost closed SLA contour and the edge of the eddy is defined as the outermost closed SLA contour which encloses no more than one eddy center. The eddy amplitude is taken to be the SLA difference between the 
eddy center and its edge, and the eddy radius is defined as the radius of a circle that has the same area as the eddy. Considering the accuracy of satellite altimetry observations, eddies with amplitude less than $3 \mathrm{~cm}$ (Chaigneau et al. 2011) are excluded in this study. Following previous studies (Chelton et al. 2011a; 2011b; He et al. 2016), only eddies with a lifespan of longer than 4 weeks are retained and analyzed in this study. Overall, 9.4 million snapshots of 127,642 anticyclonic eddies and 9.6 million snapshots of 133 , 780 cyclonic eddies are identified over the 20-year period of 1998-2017.

The eddy-induced SLAs and SST anomalies are then used in combination to distinguish CAEs and WCEs from the conventional AEs and CEs (Bashmachnikov et al. 2013; Assassi et al. 2016). An eddy is regarded as conventional if the SLA and SST anomaly at its center are of the same sign; Otherwise, the eddy is either a CAE or WCE

(Fig. 1). Note that SST anomalies at scales much smaller or larger than the eddy scale may lead to misclassification of eddies. To avoid this, we further apply a band-pass Gaussian filter to the high-pass-filtered SST anomalies inside and around each eddy with half-power cutoff wavelengths at $2 \mathrm{r}$ and $6 \mathrm{r}$ (where $\mathrm{r}$ is the radius of the eddy) to improve the accuracy of eddy classification (e.g., Fig. 1c). Additional tests show that

151 the results are not overly sensitive to slight adjustment of the half-power cutoff wavelengths. Globally, about $22 \%$ of the snapshots of AEs detected from altimeter data over the 20-year period are CAEs and about $19 \%$ of the snapshots of CEs are WCEs.

154 The large numbers of CAEs and WCEs found in this study demonstrate that CAEs and 155 WCEs are not merely a feature of curiosity as often thought, but are widespread features in the global ocean. 

bins. The conventional AEs and CEs are found to occur more frequently in the 159 extratropical regions (Figs. 2a-b), whereas the proportions of CAEs and WCEs are 160 relatively higher in the tropical regions (Figs. 2c-d). One possible explanation of this regional difference is that CAEs and WCEs in the open ocean are mainly generated by eddy-wind interaction (McGillicuddy 2015). It is well known that the relative motion between surface winds and eddy surface currents leads to anomalous Ekman upwelling (downwelling) in the center of anticyclonic (cyclonic) eddies, which can, in turn, lead to doming (depressing) of the upper ocean density surfaces inside anticyclonic (cyclonic) eddies (McGillicuddy et al. 2007; Gaube et al. 2015; McGillicuddy 2015). The magnitude of this anomalous Ekman pumping velocity is proportional to surface wind speed and inverse proportional to the magnitude of the Coriolis parameter (Gaube et al. 2015). Furthermore, the effect of eddy-wind interaction on eddy SST anomalies can be modulated by the depth of surface mixed layer; A shallow surface mixed layer makes it easier for eddy-wind interaction to modify the sign of eddy SST anomalies via the action of Ekman pumping of the upper ocean density surfaces. At low latitudes where the trade winds are relatively strong, the magnitude of the Coriolis parameter is small, and the surface mixed layer is generally shallow all year around, eddy-wind interaction can potentially convert a larger percentage of conventional AEs and CEs into CAEs and WCEs, whereas at mid latitudes the westerly winds are strongest in winter when the surface mixed layer is at its deepest, making it hard to transform conventional AEs and CEs into CAEs and WCEs (Figs. 3a-b). Indeed, there is a 
pronounced seasonal cycle in the percentages of CAEs and WCEs in extratropical oceans, which could be largely explained by the seasonal cycle of the surface mixed layer depth (Figs. 3c-d; Gaube et al. 2018). Furthermore, the large numbers of CAEs and WCEs found along the boundaries corroborate the expectation that these eddies can be generated through instability of the complex boundary flow system (Chaigneau et al. 2011; Assassi et al. 2016; Contreras et al. 2019).

\section{Three-dimensional structure}

To obtain surface eddy structures of CAEs and WCEs and the conventional AEs and CEs, we first set up an eddy coordinate system where the coordinate center is defined as the location of the eddy center and the positive $\mathrm{x}$ - and $\mathrm{y}$-axes of the coordinate correspond to the east and north directions, respectively. The high-pass-filtered satellite-derived surface anomalies such as SLAs and SST anomalies are then interpolated onto the eddy coordinate system at an interval of $0.1 \mathrm{r}$ in each direction before they are composite averaged. The composite SLAs associated with both CAEs and WCEs and the conventional AEs and CEs show the familiar Gaussian-shaped spatial pattern (Chelton et al. 2011a) and are of the same sign, albeit the magnitude of SLAs associated with CAEs and WCEs is slightly smaller (Fig. 4). Note that not visible from these global composite averages, which are normalized by the eddy radius in each direction, is that the radii of CAEs and WCEs, with averages of $85.8 \pm 39.4 \mathrm{~km}$ and 80.6 $\pm 36.9 \mathrm{~km}$, are close to those of the conventional AEs and CEs, with averages of $84.1 \pm 35.2 \mathrm{~km}$ and $84.4 \pm 35.6 \mathrm{~km}$. 

and conventional AEs and CEs are of the opposite sign, and the magnitude of SST anomalies associated with CAEs and WCEs is roughly half of those associated with conventional AEs and CEs, i.e., $\sim 0.15^{\circ} \mathrm{C}$ vs $\sim 0.35^{\circ} \mathrm{C}$ at the composite eddy centers

(Fig. 5). The SST anomalies can be further divided into a monopole pattern due to vertical eddy isothermal displacement and a dipole pattern due to lateral eddy advection of background temperature gradient (Hausmann and Czaja 2012; Gaube et al. 2015; Amores et al. 2017). Here we radially average the composite SST anomalies in Fig. 5 to obtain the monopole structure (Figs. 6a-f) which is then removed from the original SST anomalies to obtain the dipole structure (Figs. 6g-1). The resulting dipole SST anomalies associated with CAEs and WCEs and conventional AEs and CEs show almost identical patterns and magnitudes. This is consistent with the fact that SLAs associated with both types of eddies are of similar magnitude which, through geostrophic balance, results in surface lateral eddy advection of comparable strength for both CAEs and WCEs and conventional AEs and CEs (Fig. 4).

To reveal the subsurface structure of CAEs and WCEs, we conducted composite analysis involving the quality-controlled Argo float profiles over the same 20-year period. The locations of Argo profiles inside and close to the identified eddies are transformed onto the eddy coordinate system. After that, the subsurface temperature, salinity and potential density anomalies of the Argo profiles at the same depth level are objectively interpolated (Chaigneau et al. 2011; Ni et al. 2020b) onto a $0.1 \mathrm{r} \times 0.1 \mathrm{r}$ eddy 
conventional AEs and CEs are centered roughly at $150 \mathrm{~m}$ with a peak magnitude of $\sim 1.2{ }^{\circ} \mathrm{C}$ (Fig. 7). There is a westward tilt of temperature anomalies toward the sea surface (Roemmich and Gilson 2001), as a result of lateral eddy advection of background temperature gradient (Hausmann and Czaja 2012; Gaube et al. 2015; Amores et al. 2017; Fig. 6). Although the composite temperature anomalies of CAEs and WCEs are centered at almost the same depth, a much smaller peak magnitude of over $0.6^{\circ} \mathrm{C}$ is observed. Furthermore, above the temperature anomaly cores, temperature anomalies of the opposite sign are found which extend from the surface to approximately $50 \mathrm{~m}$ depth. This result shows that the cold cores of CAEs and warm cores of WCEs are largely confined in the surface mixed layer.

\section{Influence on air-sea fluxes}

Given that CAEs and WCEs and conventional AEs and CEs are associated with SST anomalies of opposite sign (Fig. 5), we expect this leads to differences in eddy-induced near-surface turbulent heat fluxes. Indeed, the composite LHF from the ocean to the atmosphere are negative over CAEs and positive over WCEs, opposite to the LHF over conventional AEs and CEs (Figs. 8a-f). The spatial pattern of composite LHF anomalies closely resembles that of composite SST anomalies. The peak magnitude of LHF anomalies associated with CAEs and WCEs $\left(\sim 2.5 \mathrm{w} \mathrm{m}^{-2}\right)$ is roughly half of that associated with conventional AEs and CEs $\left(\sim 6 \mathrm{w} \mathrm{m}^{-2}\right)$, comparable to the ratio of the magnitudes of SST anomalies between them (Fig. 5). Results on eddy-induced SHF anomalies are almost identical to those of LHF anomalies, except for a smaller 
magnitude (Figs. 8g-1).

Nearly identical patterns are found in the composite average of near-surface wind stress anomalies (Fig. 9). Therefore, the composite SST, turbulent heat flux and wind stress anomalies are all positively correlated with each other, indicating enhanced ocean heat loss and stronger wind stress over positive SST anomalies (Figs. 5 and 8). Physically, positive eddy SST anomalies induce anomalous upward surface turbulent heat fluxes, which strengthens near-surface wind and wind stress by enhancing turbulent mixing and downward momentum transport in the atmospheric boundary layer (Chelton and Xie 2010; Frenger et al. 2013; Gaube et al. 2015). This mechanism is at work for both conventional AEs and CEs and CAEs and WCEs. stress anomalies averaged over the eddy extent all display positive and near-linear relationships with the magnitudes of SLAs at the eddy centers (Figs. 10a-d), consistent with previous regional studies (e.g., Villas Bôas et al. 2015; Liu et al. 2020). However, for CAEs and WCEs, the relationships between anomalies of these three near-surface variables and eddy SLAs appear to be more complex and less linear with significantly reduced slopes (Figs. 10e-h). Such reduced slopes have also been reported for CAEs and WCEs in the South China Sea (Liu et al. 2020).

\section{Mixed layer and biological responses}


radial averages of the eddy-induced MLD anomalies diagnosed from Argo float profiles (see Section 2). Similar to previous studies which do not distinguish CAEs and WCEs from conventional AEs and CEs (Hausmann et al. 2017; Gaube et al. 2013; 2018), anticyclonic and cyclonic eddies as a whole are found to deepen and shoal the surface mixed layer, respectively, and this is dominated by contributions from conventional AEs and CEs (Figs. 11a and b). The deeper (shallower) mixed layer in anticyclonic (cyclonic) eddies can be largely explained by the enhanced (suppressed) ocean convection triggered by anomalous air-sea heat loss (gain) that results from positive (negative) SST anomalies associated with anticyclonic (cyclonic) eddies (Williams 1988; Hausmann et al. 2017; Gaube et al. 2018). In contrast, the average MLD anomalies caused by CAEs and WCEs are found to be much smaller in magnitude near the eddy centers (Fig. 11c). We attribute this to the weaker surface turbulent heat flux anomalies over CAE and WCEs compared to conventional AEs and CEs (Fig. 8) as a result of smaller SST anomalies capping CAEs and WCEs (Fig. 5), which subsequently lead to weaker anomalous convective mixing in the surface layers of CAEs and WCEs.

The biological response, e. g., chlorophyll concentration, to mesoscale eddies is complex. Whether there are positive or negative chlorophyll anomalies in the centers of anticyclonic or cyclonic eddies is region-dependent (Klein and Lapeyre 2009; Gaube et al. 2013; Dufois et al. 2016). Taking the Kuroshio Extension ([140 $-180^{\circ} \mathrm{E}$, $\left.\left.30^{\circ}-40^{\circ} \mathrm{N}\right]\right)$ and southeastern Indian Ocean $\left(\left[80^{\circ}-120^{\circ} \mathrm{E}, 20^{\circ}-30^{\circ} \mathrm{S}\right]\right)$ as examples, we composited the high-pass-filtered $\log _{10}$-transformed surface chlorophyll anomalies associated with the eddies. Conventional AEs (CEs) are found to induce negative 
(positive) surface chlorophyll anomalies in the Kuroshio Extension region, but positive (negative) chlorophyll anomalies in the southeastern Indian Ocean (Fig. 12). In both regions, the magnitude of surface chlorophyll anomalies in CAEs and WCEs is less than half of that in conventional AEs and CEs, even though CAEs and WCEs and conventional AEs and CEs are of similar strength as measured by the magnitudes of

SLAs (Fig. 4). The mechanism responsible for the weaker chlorophyll response in

CAEs/WCEs is likely to be region-dependent, e.g., Ekman upwelling/downwelling associated with eddy-wind interaction in the Kuroshio Extension region and reduced/enhanced eddy SST-induced convective mixing in the southeastern Indian Ocean.

\section{Conclusions}

Using satellite observations, we have shown for the first time that CAEs and WCEs are surprisingly abundant features in the global ocean. With temperature anomalies in the surface layer opposite in sign to those of conventional AEs and CEs, CAEs and WCEs modulate air-sea exchanges and biological processes by altering near-surface turbulent heat fluxes, wind stress, MLD and chlorophyll concentration, in a way markedly different from the conventional eddies.

Given the key importance of the air-sea boundary layer in material and energy exchange between the atmosphere and ocean interior (Chelton and Xie 2010; Frenger et al. 2013; Villas Bôas et al. 2015), CAEs and WCEs may have a distinct role to play in regulating the weather and climate system. The current common practice of 
compositing all the anticyclonic or cyclonic eddies together masks the presence of

307 CAEs and WCEs which have very different upper ocean characteristics. Given their

308 abundance, CAEs and WCEs need to be properly accounted for when assessing and

309 parametrizing the role of ocean eddies in the Earth's climate system.

310 Acknowledgments.

$311 \mathrm{X}$. Zhai is supported by a Royal Society International Exchanges Award

312 (IEC/NSFC/170007). D. Chen is supported by the National Natural Science Foundation

313 of China (41730535). We thank Peter Gaube and another anonymous reviewer for their

314 helpful comments on the earlier revision of this manuscript. 
317 The gridded altimetry and microwave data are subject to filtering process and 318 objective interpolation, which may introduce errors when distinguishing CAEs and 319 WCEs from conventional AEs and CEs. As a way to estimate the uncertainty associated 320 with our eddy classification method, we also identify CAEs and WCEs using an 321 alternative method. In this alternative method we compare the eddy SLA with SST 322 anomaly averaged within the eddy edge rather than SST anomaly at the eddy center. 323 The result shows that with the alternative method about $20 \%(18 \%)$ of the anticyclonic 324 (cyclonic) eddies identified in daily SLA snapshots are CAEs (WCEs), which is very 325 close to that estimated by our original eddy classification method. Furthermore, the 326 global distributions of CAEs and WCEs and their percentages estimated from the 327 alternative method (Fig. A1) are also very similar to those estimated from the original 328 method (Fig. 2). We, therefore, believe that the distributions and percentages of CAEs 329 and WCEs presented in this study are robust. 
Amores, A., O. V. Melnichenko, and N. Maximenko, 2017: Coherent mesoscale eddies in the North Atlantic subtropical gyre: 3-D structure and transport with application to the salinity maximum. J. Geophys. Res., 122, 23-41.

Assassi, C., and Coauthors, 2016: An index to distinguish surface- and subsurfaceintensified vortices from surface observations. J. Phys. Oceanogr., 46, 2529-2552.

Bashmachnikov, I., D. Boutov, and J. Dias, 2013: Manifestation of two meddies in altimetry and sea-surface temperature. Ocean Sci., 9, 249-259.

Bentamy, A., S. A. Grodsky, K. Katsaros, A. M. Mestas-Nuñez, B. Blanke, and F. Desbiolles, 2013: Improvement in air-sea flux estimates derived from satellite observations. Int. J. Remote Sens., 34, 5243-5261.

Chaigneau, A., M. L. Texier, G. Eldin, C. Grados, and O. Pizarro, 2011: Vertical structure of mesoscale eddies in the eastern South Pacific Ocean: A composite analysis from altimetry and Argo profiling floats. J. Geophys. Res., 116, C11025.

Chelton, D. B., and M. G. Schlax, 1996: Global observations of oceanic Rossby waves. Science, 272, 234-238.

Chelton, D. B., and S. P. Xie, 2010: Coupled ocean-atmosphere interaction at oceanic mesoscales. Oceanography, 23, 52-69.

Chelton, D. B., M. G. Schlax, and R. M. Samelson, 2011a: Global observations of nonlinear mesoscale eddies. Prog. Oceanogr., 91, 167-216. 
Chelton, D. B., P. Gaube, M. G. Schlax, J. J. Early, and R. M. Samelson, 2011b: The influence of nonlinear mesoscale eddies on near-surface oceanic chlorophyll. Science, 334, 328-332.

Contreras, M. V., O. Pizarro, B. Dewitte, H. H. Sepulveda, and L. Renault, 2019: Subsurface mesoscale eddy generation in the ocean off central Chile. J. Geophys. Res., 124, 5700-5722.

de Boyer Montégut, C., G. Madec, A. S. Fischer, A. Lazar, and D. Iudicone, 2004: Mixed layer depth over the global ocean: An examination of profile data and a profile-based climatology. J. Geophys. Res., 109, C12003.

Dilmahamod, A. F., and Coauthors, 2018: SIDDIES corridor: A major east-west pathway of long-lived surface and subsurface eddies crossing the Subtropical South Indian Ocean. J. Geophys. Res., 123, 5406-5425.

Dufois, F., N. J. Hardman-mountford, J. Greenwood, A. J. Richardson, M. Feng, and R. J. Matear, 2016: Anticyclonic eddies are more productive than cyclonic eddies in subtropical gyres because of winter mixing. Sci. Adv, , 2, 1-6.

Everett, J. D., M. E. Baird, P. R. Oke, and I. M. Suthers, 2012: An avenue of eddies: Quantifying the biophysical properties of mesoscale eddies in the Tasman Sea. Geophys. Res. Lett., 39, L16608.

Frenger, I., N. Gruber, R. Knutti, and M. Münnich, 2013: Imprint of Southern Ocean eddies on winds, clouds and rainfall. Nature Geosci., 6, 608-612.

Gaube, P., D. B. Chelton, P. G. Strutton, and M. J. Behrenfeld, 2013: Satellite 

observations of chlorophyll, phytoplankton biomass, and Ekman pumping in nonlinear mesoscale eddies. J. Geophys. Res., 118, 6349-6370.

Gaube, P., D. B. Chelton, R. M. Samelson, M. G. Schlax, and L. W. O’Neill, 2015: Satellite observations of mesoscale eddy-induced Ekman pumping. J. Phys. Oceanogr., 45, 104-132.

Gaube, P., D. J. McGillicuddy, and A. J. Moulin, 2018: Mesoscale eddies modulate mixed layer depth globally. Geophys. Res. Lett., 46, 1505-1512.

Greatbatch, R. J., X. Zhai, M. Claus, L. Czeschel, and W. Rath, 2010: Transport driven by eddy momentum fluxes in the Gulf Stream Extension region, Geophys. Res. Lett., 37, L24401.

Hausmann, U., and A. Czaja, 2012: The observed signature of mesoscale eddies in sea surface temperature and the associated heat transport. Deep-Sea Res. II, 70, 60-72.

Hausmann, U., D. J. McGillicuddy, and J. Marshall, 2017: Observed mesoscale eddy signatures in Southern Ocean surface mixed-layer depth. J. Geophys. Res., 122, 617-635.

He, Q., H. Zhan, S. Cai, and G. Zha, 2016: On the asymmetry of eddy-induced surface chlorophyll anomalies in the southeastern Pacific: the role of eddy-Ekman pumping. Prog. Oceanogr., 141, 202-211.

Klein, P., and G. Lapeyre, 2009: The oceanic vertical pump induced by mesoscale and submesoscale turbulence. Annu. Rev. Mar. Sci., 1, 351-375. 
mesoscale eddies in the Southwestern Atlantic Ocean and their dependence on different regional conditions. Clim. Dyn., 49, 2491-2501.

Liu, Y., L. Yu, and G. Chen, 2020: Characterization of sea surface temperature and airsea heat flux anomalies associated with mesoscale eddies in the South China Sea. J. Geophys. Res., 125, e2019JC015470.

McGillicuddy, D. J., 2015: Formation of intrathermocline lenses by eddy-wind interaction. J. Phys. Oceanogr., 45, 606-612.

McGillicuddy, D. J., and Coauthors, 2007: Eddy/wind interactions stimulate extraordinary mid-ocean plankton blooms. Science, 316, 1021-1026.

Ni, Q., X. Zhai, G. Wang, and C. W. Hughes, 2020b: Widespread mesoscale dipoles in the global ocean. J. Geophys. Res., 125, e2020JC016479.

Ni, Q., X. Zhai, G. Wang, and D. P. Marshall, 2020a: Random movement of mesoscale eddies in the global ocean. J. Phys. Oceanogr., 50, 2341-2357.

Roemmich, D. and J. Gilson, 2001: Eddy transport of heat and thermocline waters in the North Pacific: A key to interannual/decadal climate variability? J. Phys. Oceanogr., 31, 675-687.

Souza, J., C. de Boyer Montégut, C. Cabanes, and P. Klein, 2011: Estimation of the Agulhas ring impacts on meridional heat fluxes and transport using ARGO floats and satellite data. Geophys. Res. Lett., 38, L21602.

Stammer, D., 1997: Global characteristics of ocean variability estimated from regional TOPEX/POSEIDON altimeter measurements. J. Phys. Oceanogr., 27, 1743-1769. 
Sun, W., C. Dong, W. Tan, and Y. He, 2019: Statistical characteristics of cyclonic warmcore eddies and anticyclonic cold-core eddies in the North Pacific based on remote sensing data. Remote Sens., 11, 208.

Villas Bôas, A. B., O. T. Sato, A. Chaigneau, and G. P. Castelao, 2015: The signature of mesoscale eddies on the air-sea turbulent heat fluxes in the South Atlantic Ocean. Geophys. Res. Lett., 42, 1856-1862.

Williams, R., 1988: Modification of ocean eddies by air-sea interaction. J. Geophys. Res., 93, 15523-15533.

Xu, C., X. Zhai, and X. Shang, 2016: Work done by atmospheric winds on mesoscale ocean eddies. Geophys. Res. Lett., 43, 12174-12180.

Zhai, X., H. L. Johnson, and D. P. Marshall, 2010: Significant sink of ocean-eddy energy near western boundaries. Nat. Geosci., 3, 608-612. 

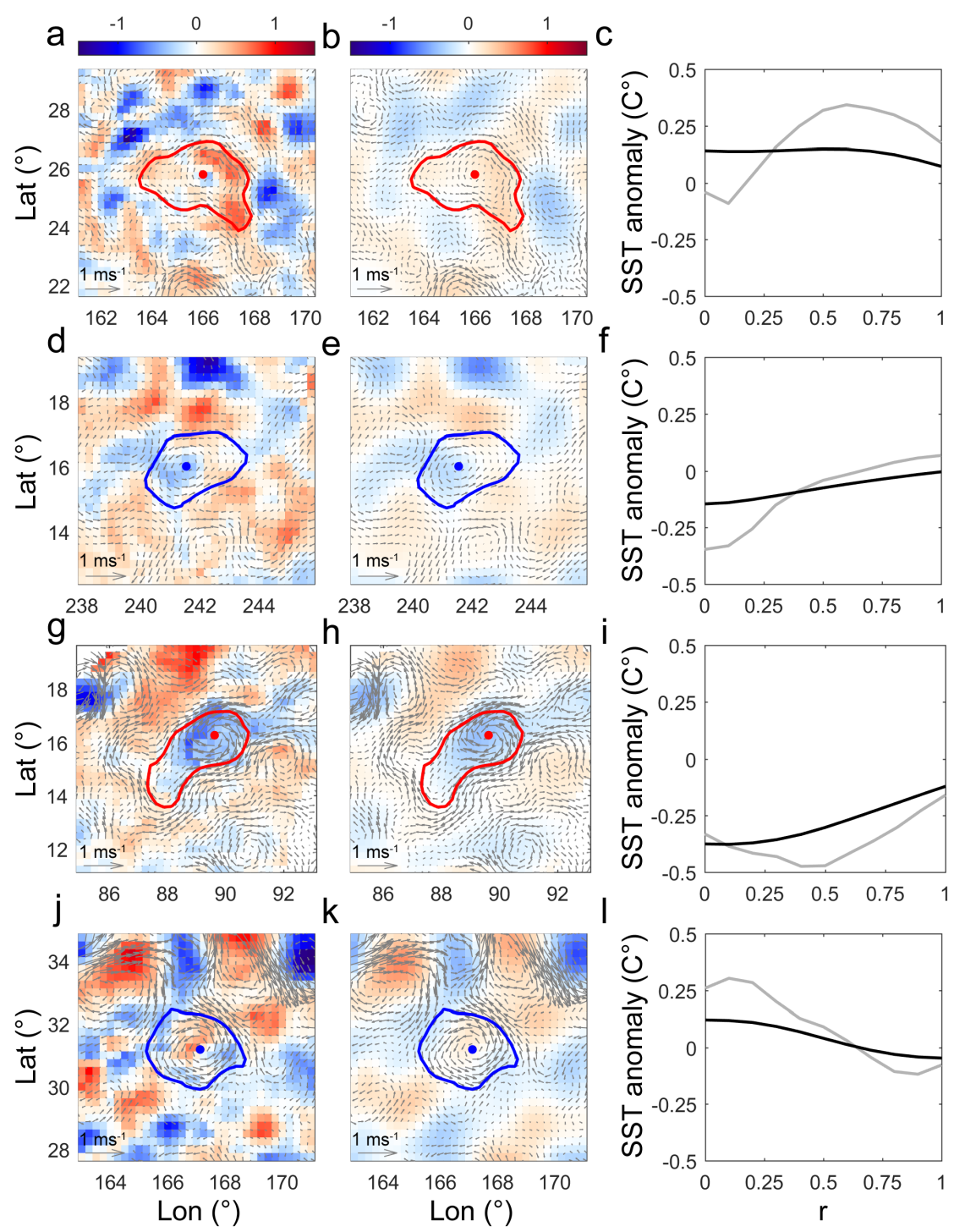

FIG. 1. Examples of (a-c) conventional anticyclonic eddies (AEs; red) and (d-f)

429 conventional cyclonic eddies (CEs; blue) identified from a combination of sea level

430 anomaly (SLA) and sea surface temperature (SST; ${ }^{\circ} \mathrm{C}$ ) anomaly maps on January 1 st

4312000 , with eddy centers (edges) denoted by dots (closed contours). Arrows and colour

432 shadings indicate surface geostrophic currents and SST anomalies, respectively. Grey

433 (black) curves show radial averages of SST anomalies with wavelengths smaller than

$4346^{\circ}$ (of 2r-6r) inside eddy edges highlighted in the left (middle) column, where the radius 


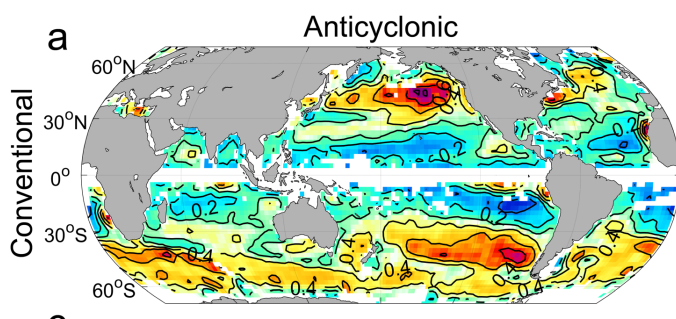

C

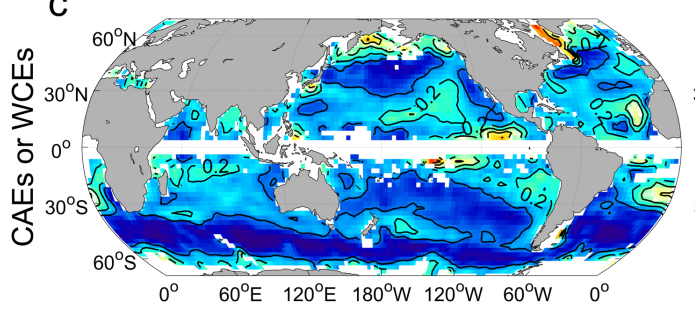

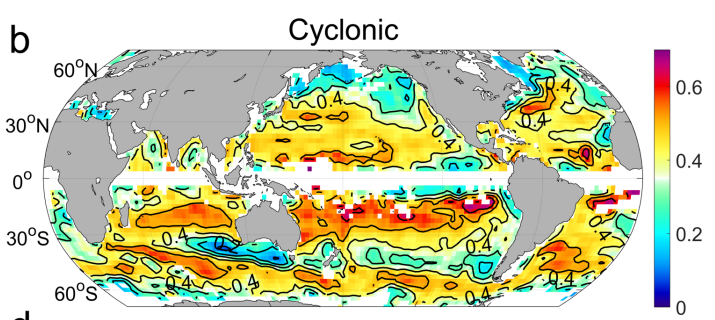

d

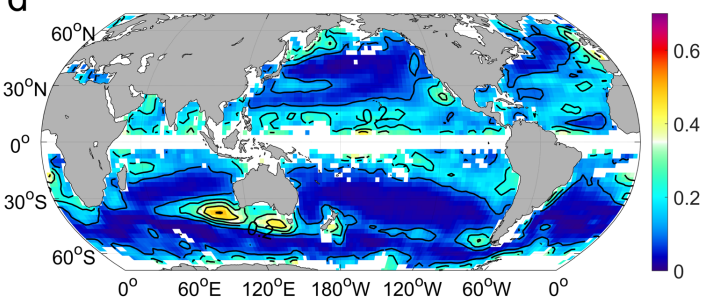

439 FIG. 2. Proportions of different types of mesoscale eddies in global $2^{\circ} \times 2^{\circ}$ bins. The

440 ratio of the number of snapshots of (a) conventional AEs, (b) conventional CEs, (c)

441 CAEs and (d) WCEs to the total number of snapshots of eddies detected in each bin over the 20-year period of 1998-2017. 

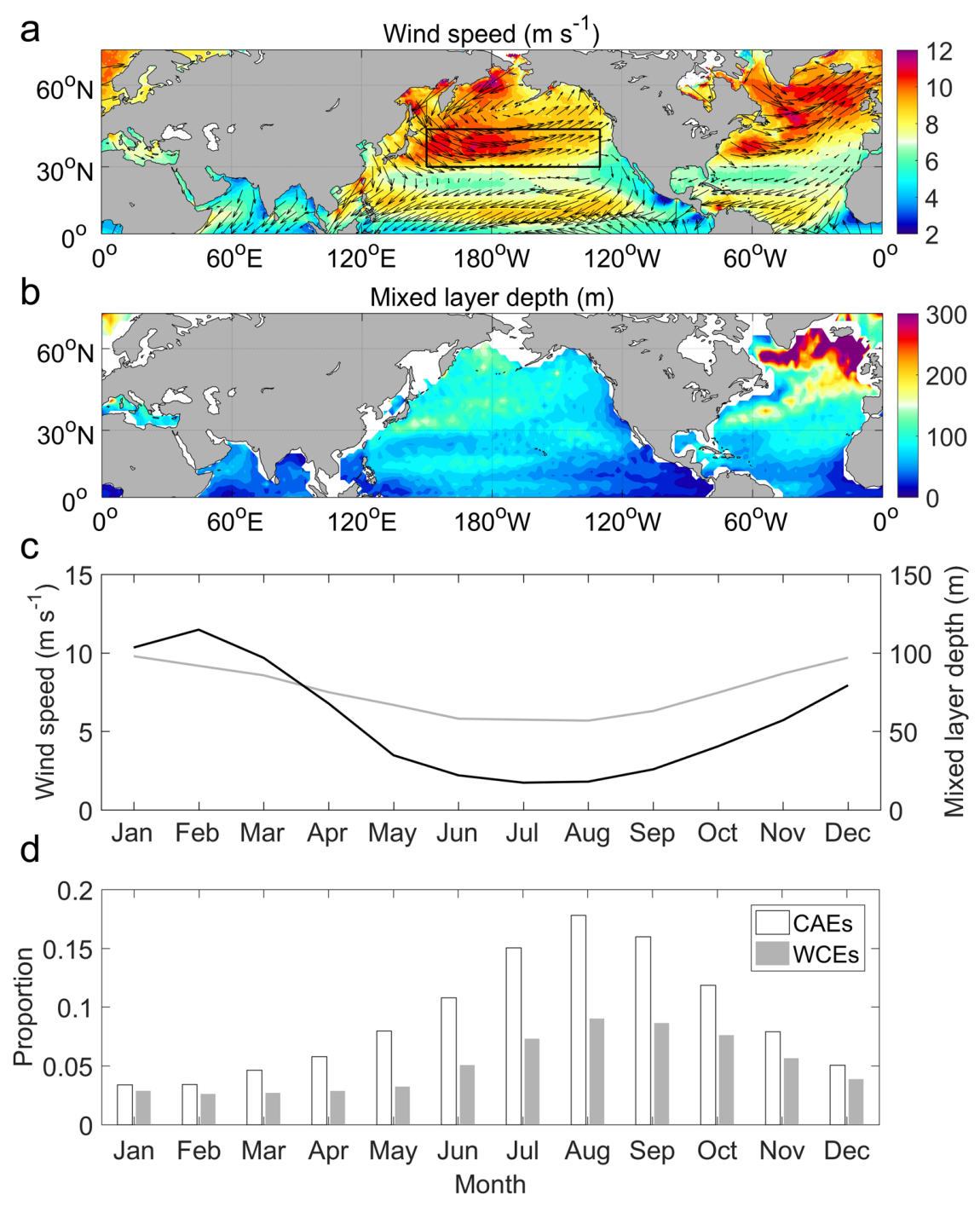

444 FIG. 3. (a) Wind speed (colour) and wind direction (arrows), and (b) mixed layer depth 445 averaged over the northern hemisphere winter (December to February) in $2^{\circ} \times 2^{\circ}$ bins.

446 Seasonal cycles of (c) the wind speed (grey) and mixed layer depth (black) and (d) the 447 proportions of CAEs and WCEs averaged in the midlatitude North Pacific $448\left(\left[150^{\circ}-230^{\circ} \mathrm{E}, 30^{\circ}-45^{\circ} \mathrm{N}\right]\right)$ as indicated by the black box in Fig. 3a. 


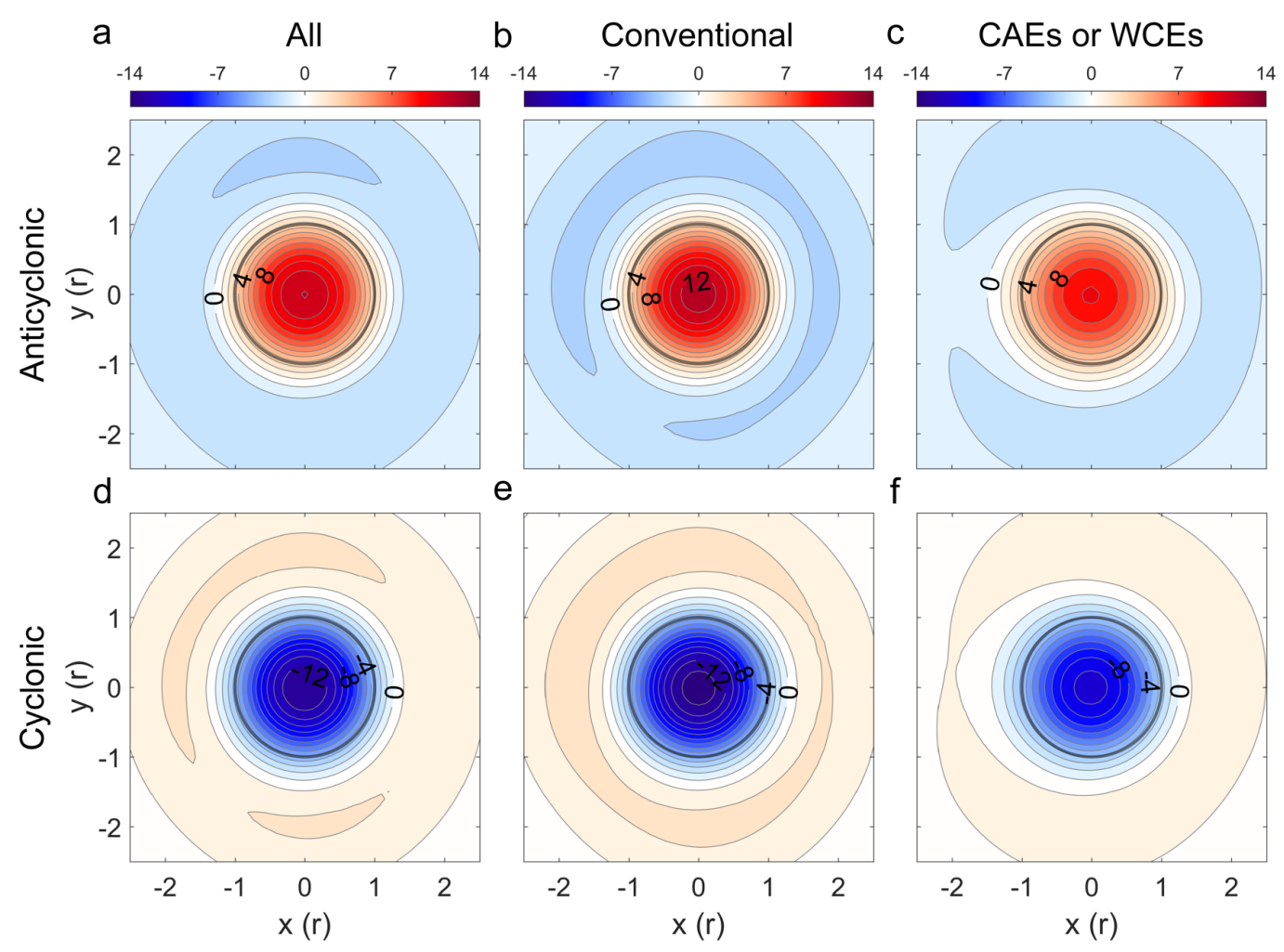

449

FIG. 4. Composite averages of SLA (cm) inside and around (a) all the anticyclonic

451 eddies, (b) conventional AEs, (c) CAEs, (d) all the cyclonic eddies, (e) conventional

CEs and (f) WCEs in the global ocean. Black bold circles indicate one eddy radius. 


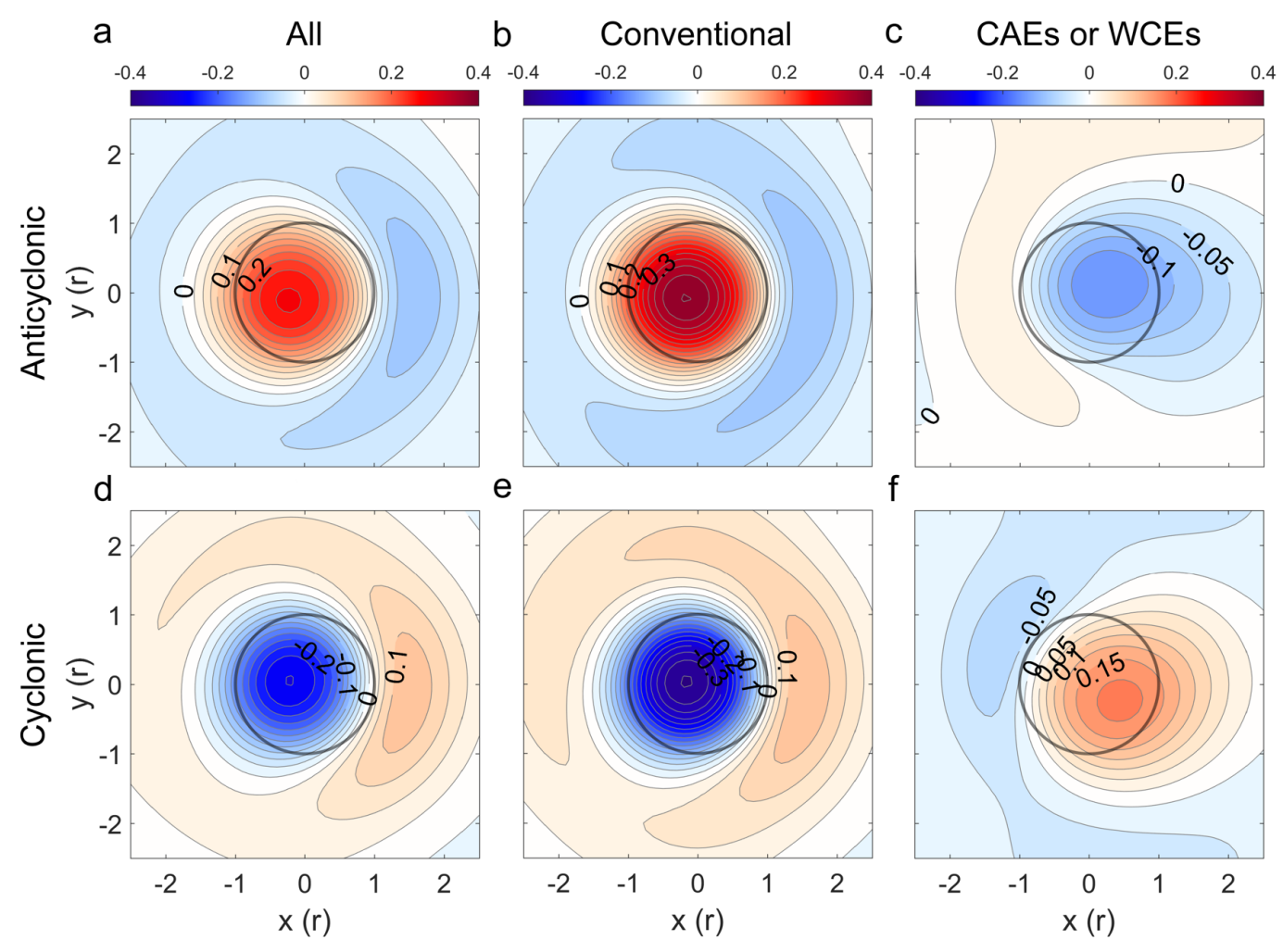

453

454 FIG. 5. Same as Fig. 4 but for SST anomalies $\left({ }^{\circ} \mathrm{C}\right)$. 

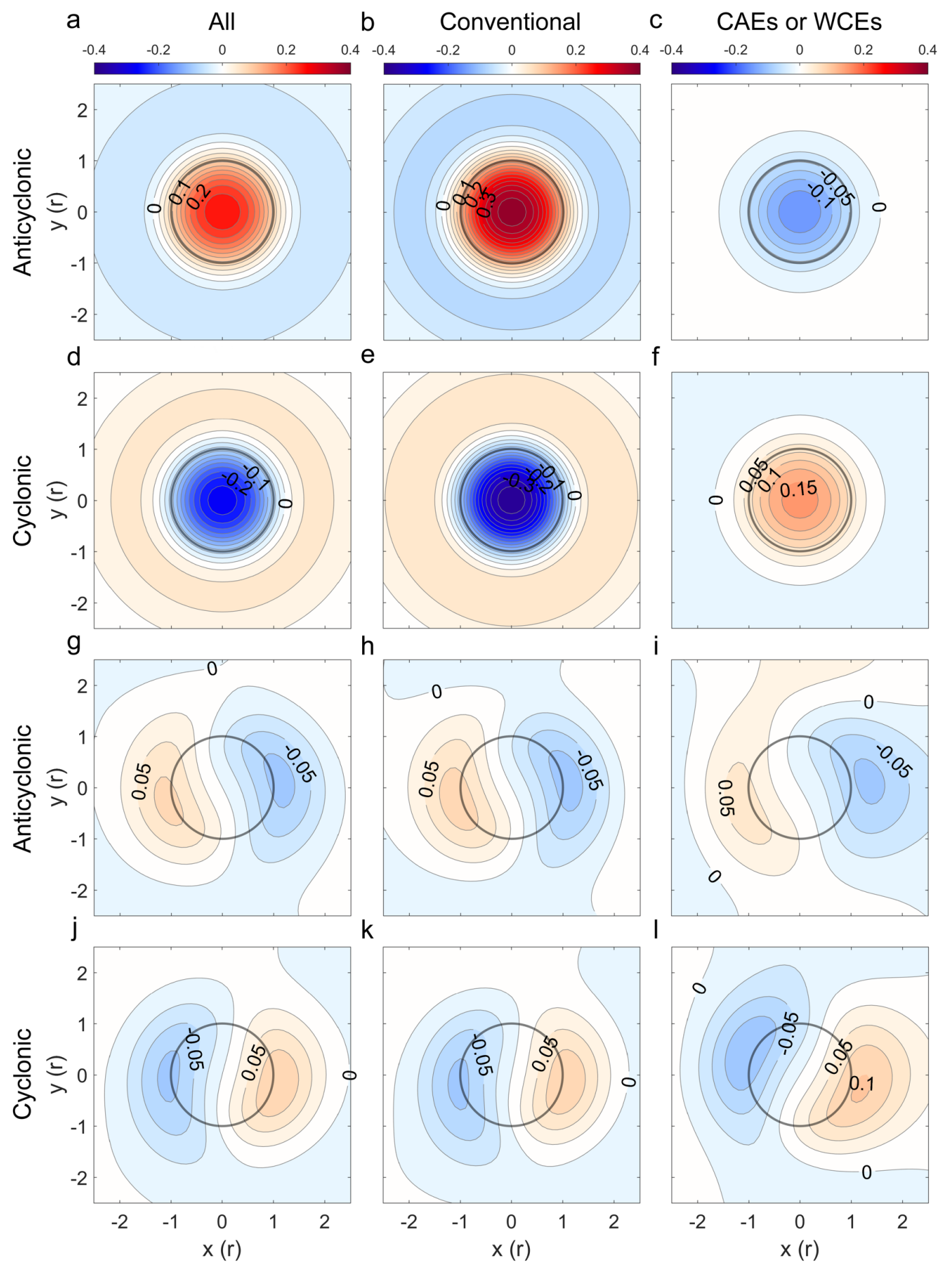

456 FIG. 6. Dividing the composite SST anomalies $\left({ }^{\circ} \mathrm{C}\right)$ shown in Fig. 5 into (a-f) monopole 457 and (g-1) dipole patterns. 


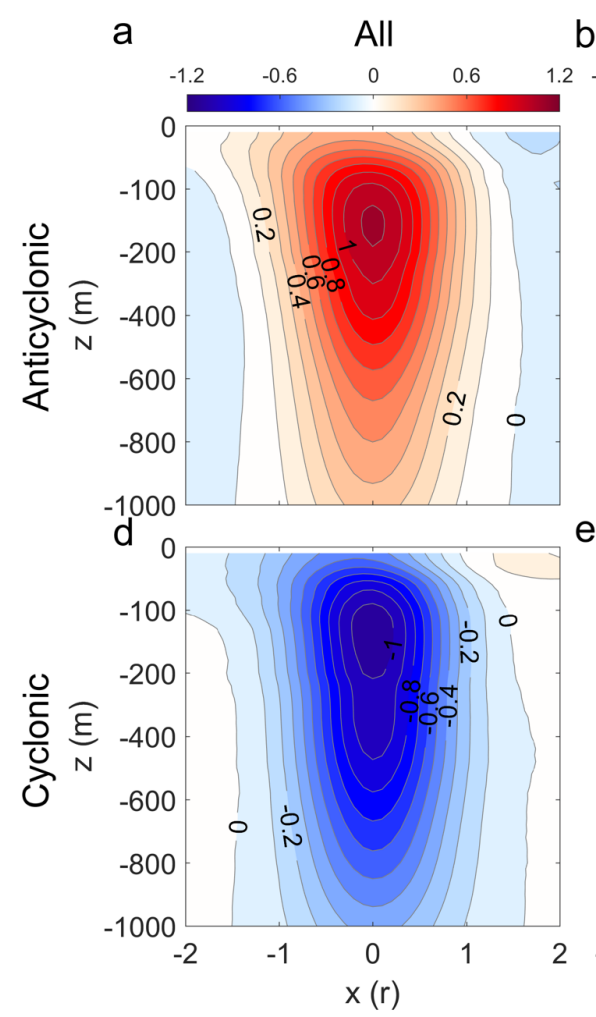

458

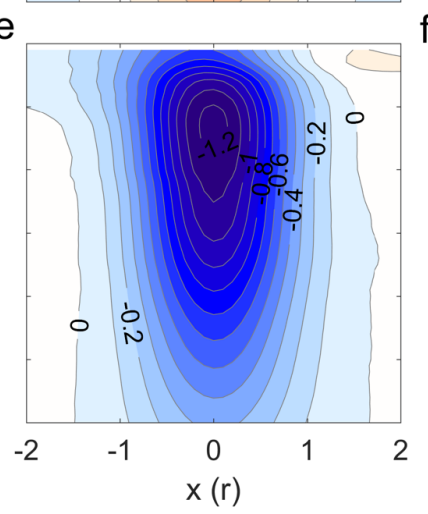

C CAES or WCEs

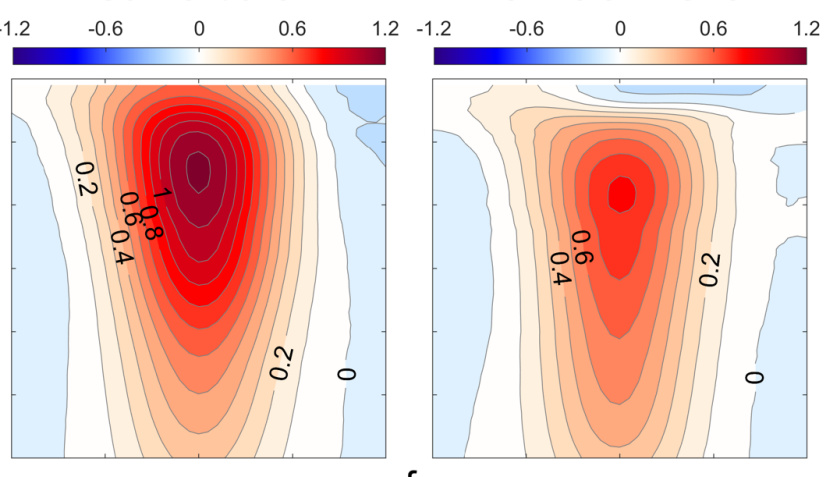

f

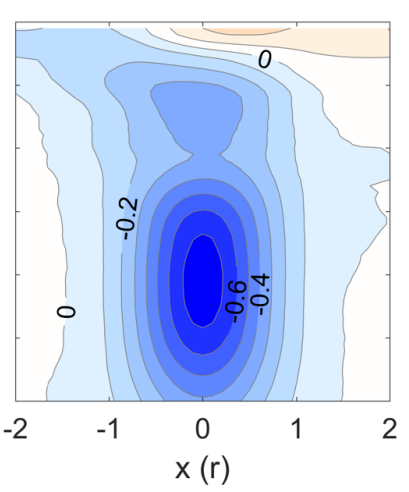

459 FIG. 7. Vertical sections of composite eddy temperature anomalies $\left({ }^{\circ} \mathrm{C}\right)$ along $\mathrm{y}=0$ for

460 (a) all the anticyclonic eddies, (b) conventional AEs, (c) CAEs, (d) all the cyclonic 461 eddies, (e) conventional CEs and (f) WCEs. Note that an uneven vertical scale is used 462 here. 

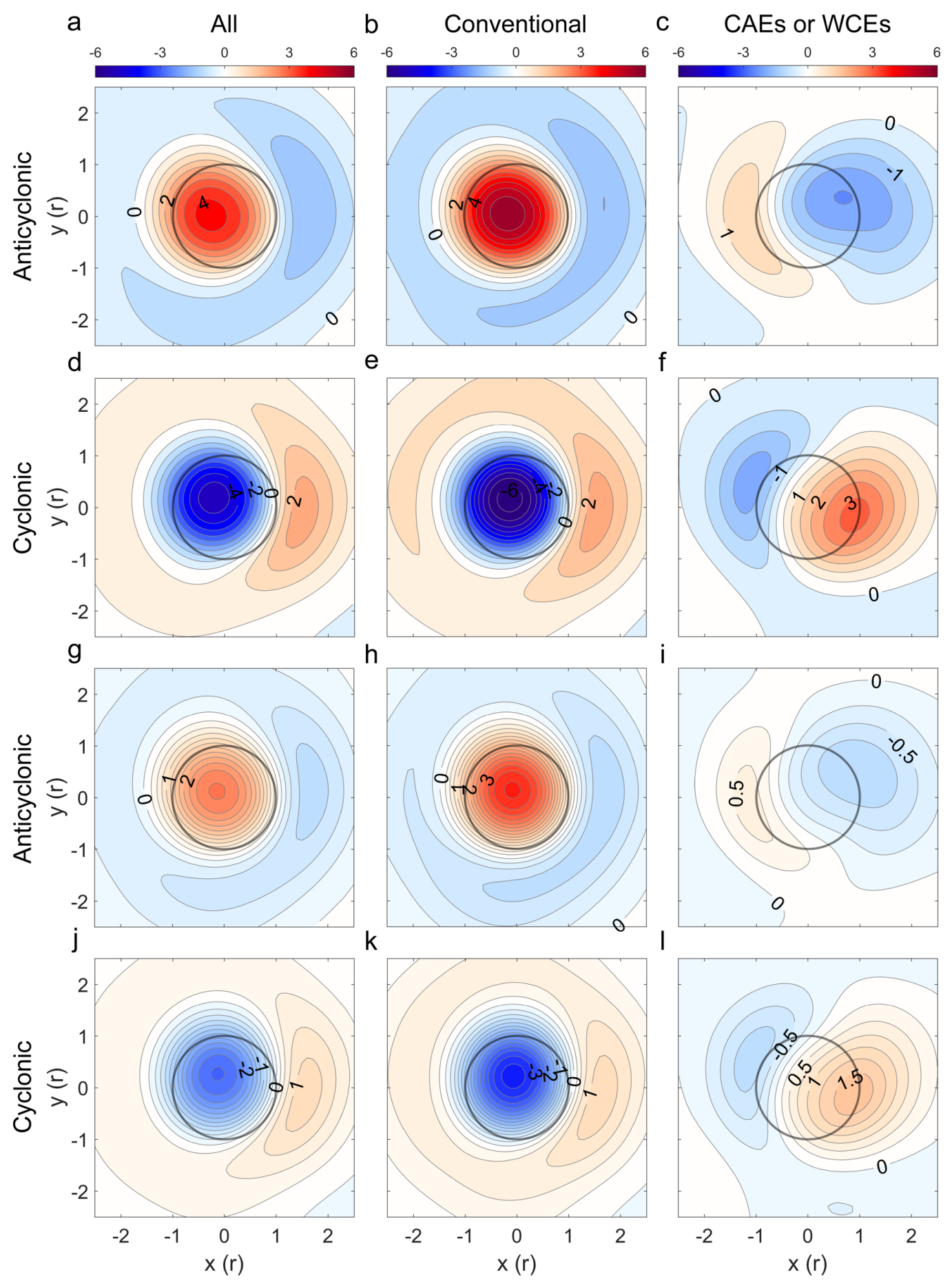

464 FIG. 8. Same as Fig. 4 but for (a-f) latent heat flux (LHF) anomalies ( $\left.\mathrm{w} \mathrm{m}^{-2}\right)$ and (g-l) 465 sensible heat flux (SHF) anomalies $\left(\mathrm{w} \mathrm{m}^{-2}\right)$. 

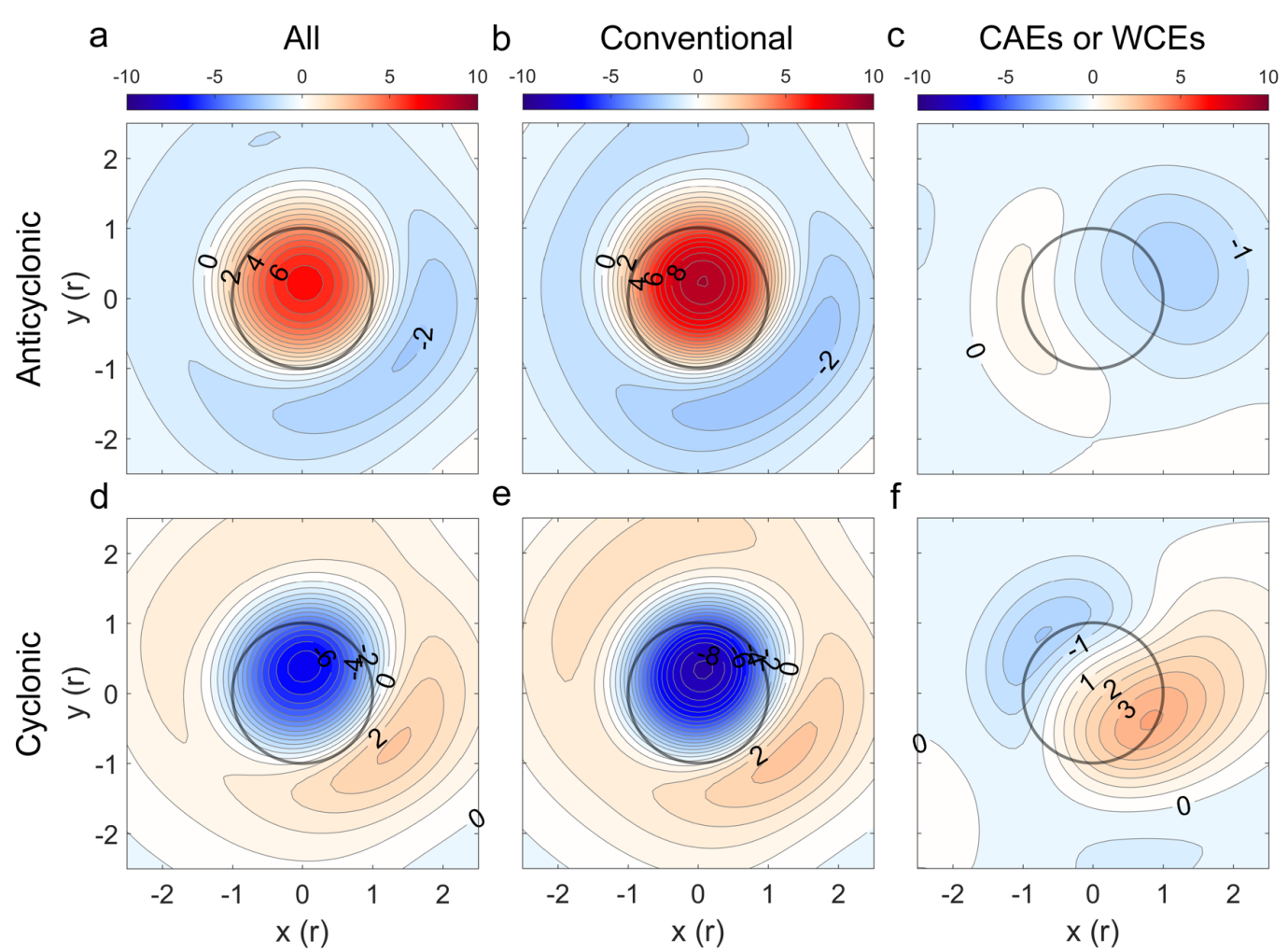

466

467 FIG. 9. Same as Fig. 4 but for near-surface wind stress anomalies $\left(10^{-3} \mathrm{~N} \mathrm{~m}^{-2}\right)$. 

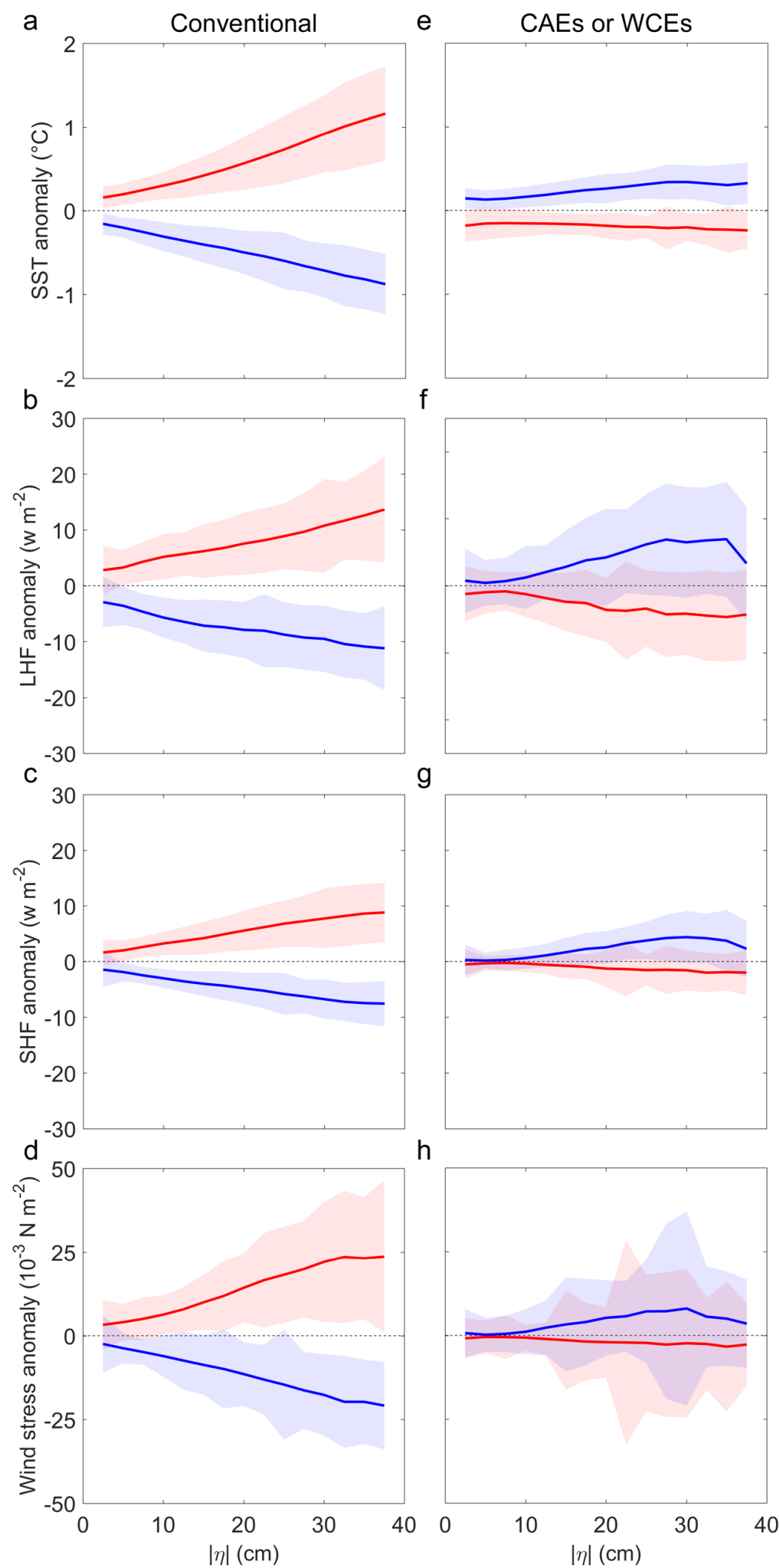

469 FIG. 10. (a) $\operatorname{SST}\left({ }^{\circ} \mathrm{C}\right)$, (b) LHF $\left(\mathrm{w} \mathrm{m}^{-2}\right)$, (c) SHF $\left(\mathrm{w} \mathrm{m}^{-2}\right)$, and (d) wind stress $\left(10^{-3} \mathrm{~N}\right.$ $470 \mathrm{~m}^{-2}$ ) anomalies as a function of absolute SLA (cm) at the centers of conventional AEs 
471 (red) and CEs (blue) averaged in the global ocean. Colour shadings indicate one 472 standard deviation of the global $10^{\circ} \times 10^{\circ}$ bins. (e-h) Same as Figs. 12a-d but for CAEs 473 and WCEs.
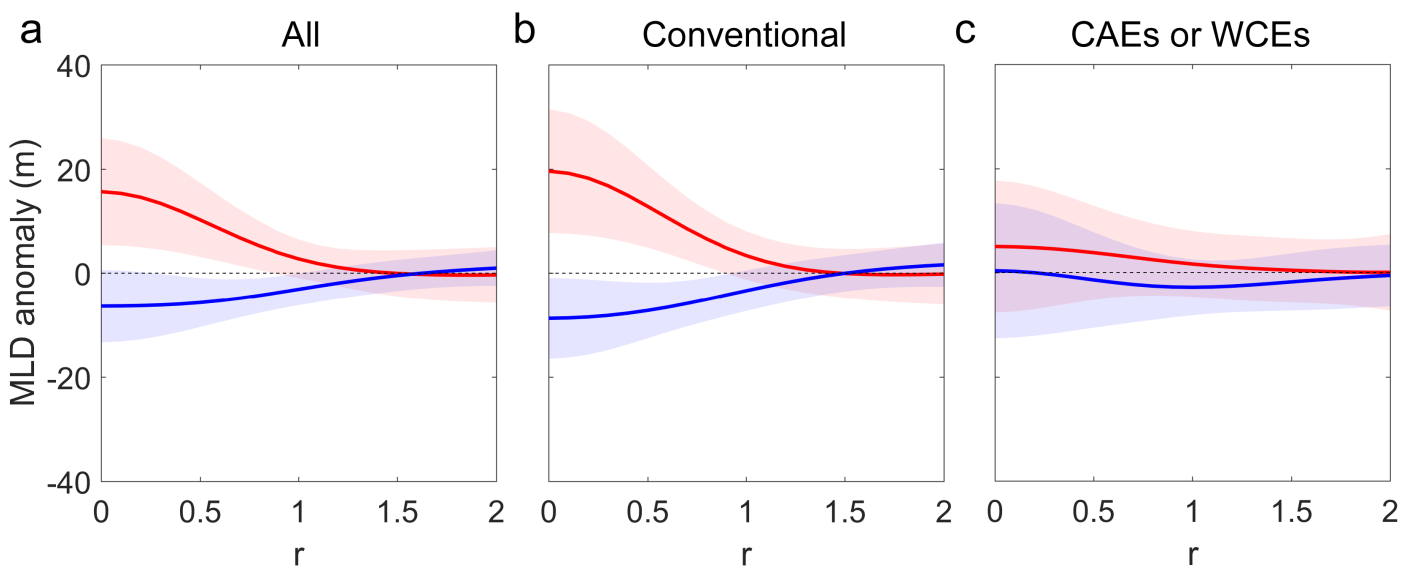

474

475 FIG. 11. Radial profiles of mixed layer depth anomalies (m) induced by anticyclonic

476 (red curves) and cyclonic (blue curves) eddies averaged in the global ocean during the

47720 -year period. Colour shadings indicate one standard deviation of the global $10^{\circ} \times 10^{\circ}$ 478 bins. 

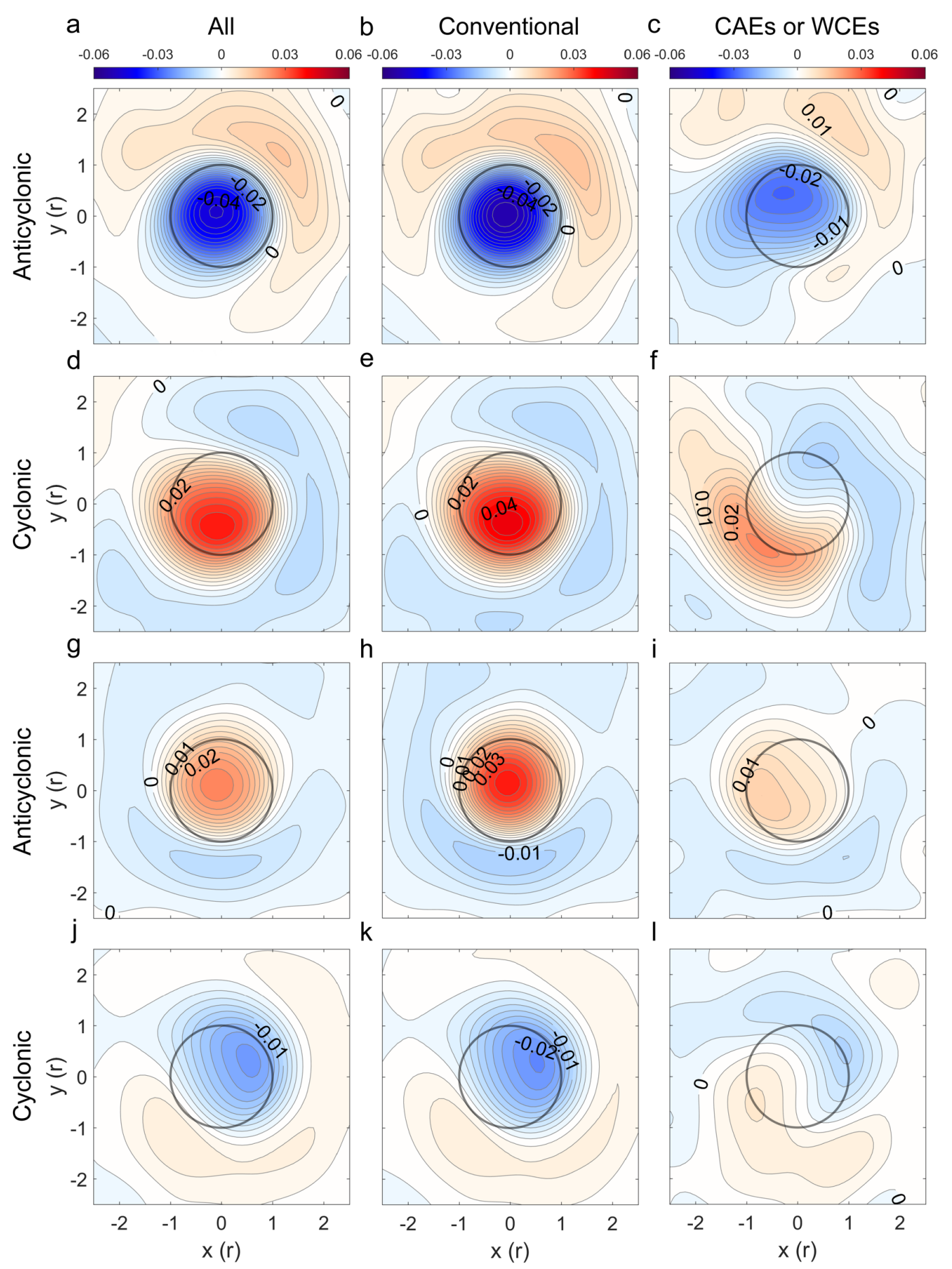

FIG. 12. Same as Fig. 4 but for the $\log _{10}$-transformed chlorophyll concentration $\left(\mathrm{mg} \mathrm{m}^{-}\right.$

$48 \mathrm{~S}^{3}$ ) anomalies associated with the eddies in (a-f) the Kuroshio Extension region $482\left(\left[140^{\circ}-180^{\circ} \mathrm{E}, 30^{\circ}-40^{\circ} \mathrm{N}\right]\right)$ and $(\mathrm{g}-1)$ the southeastern Indian Ocean $\left(\left[80^{\circ}-120^{\circ} \mathrm{E}\right.\right.$, $\left.\left.20^{\circ}-30^{\circ} \mathrm{S}\right]\right)$ 


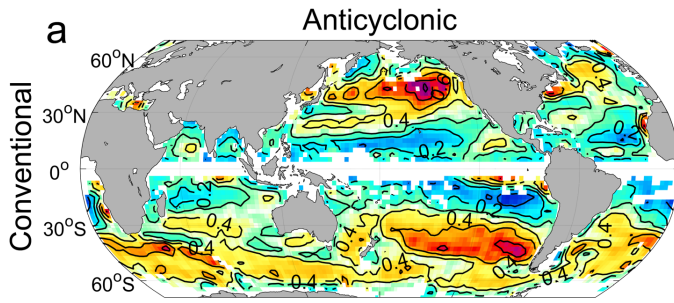

\section{$\mathrm{C}$}

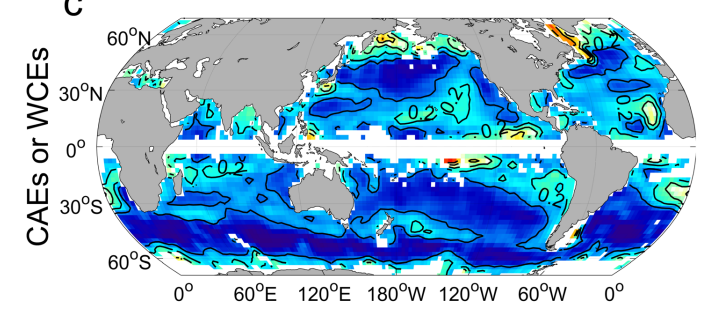

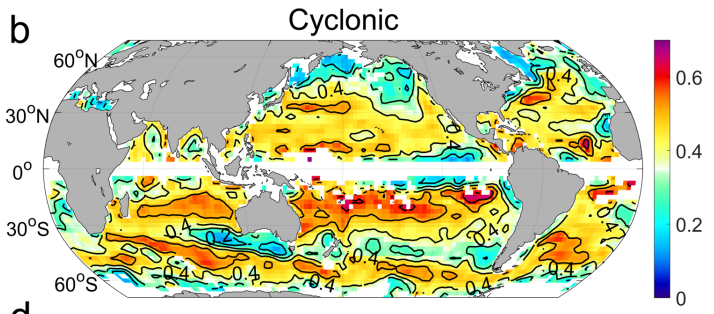

d

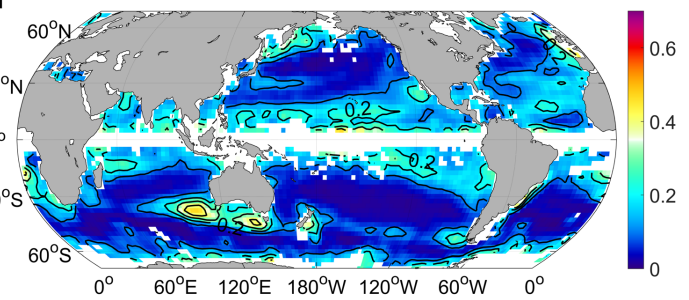

485 FIG. A1. Same as Fig. 2 but with CAEs and WCEs identified using an alternative

486 method of comparing the eddy SLA with SST anomaly averaged within the eddy edge

487 rather than SST anomaly at the eddy center. 